\title{
Contribution of diet and major depression to incidence of acute myocardial infarction (AMI)
}

\author{
Teymoor Yary ${ }^{1}$, Kourosh Soleimannejad ${ }^{2 *}$, Firdaus Abd Rahim ${ }^{3}$, Mirnalini Kandiah', Sanaz Aazami ${ }^{4}$, \\ Seyedehozma Jafar Poor ${ }^{2}$, Wong Teck Wee ${ }^{3}$, Golnaz Aazami ${ }^{4}$
}

\begin{abstract}
Background: Despite significant improvements in the treatment of coronary heart disease (CHD), it is still a major cause of mortality and morbidity among the Iranian population. Epidemiological studies have documented that risk factors including smoking and the biochemical profile are responsible for the development of acute myocardial infarction (AMI). Psychological factors have been discussed as potential risk factors for coronary heart disease. Among emotional factors, depression correlates with coronary heart disease, particularly myocardial infarction.

Methods: This case-control study was conducted on 120 cases (69 males and 51 females) of acute myocardial infarction (AMI) and 120 controls, with a mean age of $62.48 \pm 15.39$ years. Cases and controls were matched by age, residence and sex.

Results: The results revealed that severe depression was independently associated with the risk of $A M I(P=0.025$, $\mathrm{OR}=2.6,95 \% \mathrm{Cl}$ 1.1-5.8). The analysis of variables indicated that risk factors for developing depression were unmarried, low levels of polyunsaturated fatty acids (PUFAs), total dietary fiber (TDF) and carbohydrates. The levels of these dietary factors were lowest in severely depressed patients compared to those categorised as moderate or mild cases. Furthermore, severely depressed subjects were associated with higher levels of total cholesterol, high systolic blood pressure (SBP) and WHR. Age, income, a family history of coronary heart disease, education level, sex, employment and smoking were not associated with severe depression.
\end{abstract}

Conclusion: The present study demonstrated that severe depression symptoms are independent risk factors for AMI. Furthermore, severe depression was associated with an unhealthy diet and AMI risk factors.

\section{Background}

Despite significant improvements in the treatment of coronary heart disease (CHD), it is still a major cause of mortality and morbidity among the Iranian population [1]. Epidemiological studies have documented that risk factors including smoking and the biochemical profile are responsible for the development of acute myocardial infarction (AMI) [2-4].

Psychological factors have been discussed as potential risk factors for coronary heart disease [5]. Among emotional factors, depression correlates with coronary heart disease, particularly myocardial infarction [6]. Major depression has been associated with approximately $20 \%$ of patients newly diagnosed with CHD, and with

\footnotetext{
* Correspondence: korkajs@yahoo.com

2Department of Medicine, Faculty of Medicine and Health Sciences, Ilam

Medical University, 6939177143, Banganjab, llam, Iran

Full list of author information is available at the end of the article
}

patients who have suffered but recovered from myocardial infarction (MI) [7]. Depression has been related to various heart disease risk factors such as an unhealthy diet $[8,9]$, anthropometric parameters, marital dissatisfaction [10], and hypertension [11,12]. Many MI patients say they continue to smoke and persist with an unhealthy diet because of depression, despite these being well-known risk factors for MI [13]. While depression appears to be a risk factor for myocardial infarction, it is not clear whether it should be considered as an independent risk factor for this disease [14].

The aim of the present study was to investigate the association of severe depression and AMI risk factors such as diet. In addition, we aimed to assess, after adjusting for other variables, whether severe depression is an independent risk factor for acute myocardial infarction (AMI). 


\section{Materials and methods}

This study was approved by the Ethics Committee of the University Putra Malaysia and informed consent was obtained from all participants before enrolment in the study.

\section{Study subjects and study design}

This case-control study was conducted on 120 cases (69 males and 51 females) of acute myocardial infarction (AMI) and 120 controls, with a mean age of $62.48 \pm$ 15.39 years. AMI was defined by clinical criteria, electrocardiographic criteria and biochemical markers. Cases of AMI were recruited from individuals who suffered from chest pain and were admitted to the emergency department of Mostafa hospital. Control cases comprised 120 individuals who received routine health checkups at the same hospital. Cases and controls were matched by age, residence and sex. Exclusion criteria included notable chronic medical illness (e.g. untreated hyperthyroidism or hyperthyroidism, renal disease or malignant disease, and pregnancy) as these conditions could change an individual's lifestyle or modify the risk factors for AMI. Cases and controls that had a history of mental illness and received anti-depressants or other psychiatric drugs were excluded. Furthermore, controls who had positive electrocardiographic results were excluded.

\section{Determination of dietary variables}

A semi-quantitative food frequency questionnaire (FFQ) developed by Willet [15] and validated extensively in several multi-ethnic populations was used to collect dietary information. The FFQ was used to measure long-term (over the previous 12 months) intake of food. The list of foods in the FFQ was modified to reflect the traditional diet of the Ilam province. The FFQ data were obtained during a face-to-face interview with subjects. Nutrition IV software version 3.5.2 was used for analysis of nutrient intake. The database included a standard reference, which contained several different foods and nutrients, and values for nutrients such as carbohydrates and fats.

\section{Determination of biomarkers}

The venous blood of participants was collected by a nurse at the Mostafa Hospital between 07.00 and 09.00 hours, 12-14 hours after an overnight fast, and centrifuged between 30 to 40 minutes after collection; blood samples from AMI patients were collected within 24 hours of fasting. Fasting levels of serum total cholesterol (TC), triglycerides (TG), low density lipoproteins (LDL), high density lipoproteins (HDL) and fasting blood sugar (FBS) were determined using standard laboratory methods at the Mostafa Hospital, Ilam. Fasting blood sugar (FBS) and lipid profiles were measured using the Pars Azmoon Kit, which has been described in earlier studies $[16,17]$.

\section{Blood pressure}

A standard manometer was used by a nurse or physician to measure the blood pressure (BP) of participants. The first BP readings were taken with individuals in the sitting position and after five minutes rest. Two separate readings for the blood pressure of each participant were taken with a 10-minute interval between them. The averages of these readings were recorded and used for final data analysis.

\section{Depression questionnaire}

The present study used the Centre for Epidemiological Studies Depression Scale (CES-D) to measure depression. The CES-D was translated into Persian by the researcher and used to obtain the cut off point for this study.

The CES-D scale was originally developed to measure depression. The Centre for Epidemiological Studies developed the questionnaire with a 20-interview format or self-report items for the purpose of measuring current levels of symptoms of depression. These items included appetite loss, sleep disorders, sadness, crying, feelings of loneliness and fear. The CES-D 4-point scale is: $0=$ rarely or none of the time (less than 1 day); $1=$ some or a little of the time (1-2 days); $2=$ occasionally or a moderate amount of time (3-4 days); $3=$ most or all of the time (5-7 days).

Four items $(4,8,12$, and 16) in this questionnaire were reversed. The total depression score was calculated by summing up the item scores. Generally, average scores were between 0 and 60 , and higher scores indicated more depressive symptoms. For the high depressive symptoms category a cut-off score of 21 was used as a determinant of severe depression. The baseline characteristics for depression status were established in the controls, and depression in positive cases was assessed after three months.

\section{Statistical analysis}

SPSS for Windows version 18 was used for statistical analyses. Cases and controls were compared using parametric and non-parametric tests including chi-square test, independent sample t-test and the Mann-Whitney $\mathrm{U}$ test. For final analysis, binary unconditional logistic regression analysis was conducted to identify severe depression as an independent risk factor for AMI in the case-control model.

\section{Results}

The mean age of the participants was $62.48 \pm 15.39$ years and Table 1 presents the baseline variable data for the 240 participants (120 cases and 120 controls). Univariate analysis of continuous variables indicated that risk factors for developing AMI were low TDF, WHR, 
Table 1 Baseline variables for cases and controls

\begin{tabular}{llll}
\hline Variables & $\begin{array}{l}\text { Cases } \\
(\mathbf{n}=\mathbf{1 2 0}) \\
\text { Mean } \pm \text { SD }\end{array}$ & $\begin{array}{l}\text { Controls } \\
(\mathbf{n}=\mathbf{1 2 0}) \\
\text { Mean } \pm \text { SD }\end{array}$ & $\mathbf{p}$ \\
\hline Family history of CHD,\% & 36.7 & 10.8 & 0.000 \\
Current smoker, \% & 22.5 & 8.3 & 0.002 \\
Former smoker, \% & 12.5 & 7.5 & 0.197 \\
Married, \% & 78.3 & 91.7 & 0.004 \\
Education $\geq$ higher & 22.5 & 30.0 & 0.187 \\
secondary school, \% & & & \\
Employed, \% & 51.7 & 71.7 & 0.001 \\
SBP (mm/Hg) & $150.05 \pm 14.92$ & $139.17 \pm 19.78$ & 0.000 \\
Income (\$) & $409.25 \pm 194.15$ & $395.41 \pm 199.61$ & 0.587 \\
DBP (mm/Hg) & $98.76 \pm 11.28$ & $91.65 \pm 13.04$ & 0.000 \\
FBS (mg/dl) & $129.89 \pm 75.58$ & $100.60 \pm 32.23$ & 0.000 \\
TC (mg/dl) & $217.45 \pm 30.22$ & $184.65 \pm 36.19$ & 0.000 \\
TG (mg/dl) & $177.62 \pm 97.53$ & $143.64 \pm 41.68$ & 0.001 \\
LDL-C (mg/dl) & $151.84 \pm 24.55$ & $135.55 \pm 23.63$ & 0.000 \\
HDL-C(mg/dl) & $62.70 \pm 12.77$ & $59.74 \pm 12.18$ & 0.109 \\
TDF (g/day) & $12.89 \pm 5.71$ & $17.63 \pm 6.36$ & 0.000 \\
Carbohydrates (g/day) & $219.05 \pm 56.54$ & $259.12 \pm 59.27$ & 0.000 \\
SFA (g/day) & $17.32 \pm 5.83$ & $17.86 \pm 6.36$ & 0.488 \\
MUFA (g/day) & $16.51 \pm 5.92$ & $19.20 \pm 6.20$ & 0.001 \\
PUFA (g/day) & $13.61 \pm 10.14$ & $16.93 \pm 9.91$ & 0.011 \\
WHR & $1.04 \pm 0.18$ & $0.97 \pm 0.20$ & 0.006 \\
BMI (kg/m ${ }^{2}$ ) & $28.70 \pm 5.36$ & $27.96 \pm 5.24$ & 0.280 \\
\hline & & &
\end{tabular}

FBS, TC, TG, LDL, SBP, DBP, MUFA and PUFA. A family history of coronary artery disease and smoking increased the risk of developing AMI. Most of the subjects enrolled in the study had not been educated to the level of higher secondary school or beyond and most were also married. There were no significant differences in terms of education level and marital status between the experimental and control groups.

The participants were divided according to the absence or presence of severe depression symptoms, calculated from the total depression questionnaire. The prevalences of severe depression in the case and control groups were $36.7 \%$ and $15.8 \%$, respectively. The present study demonstrated that severe depression was significantly associated with unmarried subjects. Further analyses demonstrated no significant differences between the groups in terms of relationships between severe depression, a family history of coronary heart disease, education level, sex, employment and smoking (Table 2).

The analysis of variables indicated that risk factors for developing depression were low levels of polyunsaturated fatty acids (PUFAs), total dietary fiber (TDF) and carbohydrates. The levels of these dietary factors were lowest in severely depressed patients compared to those categorised as moderate or mild cases. Furthermore, severely depressed subjects were associated with higher levels of total cholesterol, high systolic blood pressure (SBP) and WHR. Age and income were not associated with severe depression (Table 3).

Table 4 presents crude and adjusted data concerning severe depression associated with AMI. The results revealed that severe depression was independently associated with the risk of AMI $(\mathrm{P}=0.025, \mathrm{OR}=2.6,95 \%$ CI 1.1-5.8).

\section{Discussion}

This study has demonstrated that severe depression symptoms are independently associated with AMI, after adjusting for other factors. In addition, lower total dietary fiber (TDF), carbohydrates, higher levels of total cholesterol (TC), a high waist-hip ratio (WHR) and high systolic blood pressure (SBP) were associated with individuals exhibiting severe depression symptoms.

After the war between Iran and Iraq between 1980 and 1988, psychological illness increased and it is reported that 60,000 suffer from such conditions [18]. There is a high incidence of suicide [19], believed to reflect the high levels of depression in this region. However, there may be reasons other than genetic factors and the war that cause depression in this population including poor living conditions and a lack of amenities for the general population [20].

Several studies have demonstrated that depression is associated with higher morbidity and mortality in patients with AMI [13,21-23]. In addition, patients who suffer from myocardial infarction (MI) commonly experience major depressive disorders [24]. For example, after adjusting for other risk factors, the risk of mortality for acute myocardial infarction is as much as four times higher because of major depression [25].

Mechanisms underlying the relationship between depression and CHD have yet to be elucidated. However, abnormal levels of biomedical coronary risk factors and neurohormonal dysregulation could explain why depression increases the occurrence of CHD or predicts its clinical outcome. Depressed subjects often exhibit more AMI risk factors including hypertension [26], and hyperlipidemia than those without depression [27].

Major depressive disorders can deregulate the autonomic nervous system (ANS) and the hypothalamicpituitary-adrenal (HPA) axis, and this deregulation can result in elevated catecholamines and cortisol [21,23], The ANS down-regulation predisposes patients to myocardial ischemia owing to activated platelet factors [28], such as cytokines and growth factors. These factors accelerate atherosclerosis through the migration and adhesion of leukocytes, the promotion of oxidized LDL and free radicals [29].

Furthermore, HPA hyperactivity during depression alters the blood brain barrier by deregulation of the 
Table 2 Categorical variables based on depression levels

\begin{tabular}{lccc}
\hline Variables & \multicolumn{2}{c}{ Severe Depression } & \\
& Absent (N = 177) & Present (N = 63) & p \\
\hline Case group/control group, \% & $63.3 / 84.2$ & $36.7 / 15.8$ & 0.000 \\
Married, \% & 89.3 & 73.0 & 0.002 \\
Education $\geq$ higher secondary school, \% & 27.7 & 22.2 & 0.398 \\
Sex, \% & & & \\
$\quad$ Female & 44.1 & 38.1 & 0.410 \\
$\quad$ Male & 55.9 & 61.9 & \\
Employed, \% & 62.1 & 60.3 & 0.798 \\
Family history of CHD, \% & 23.7 & 23.8 & 0.990 \\
Current smoker, \% & 15.3 & 15.9 & 0.907 \\
Former smoker,\% & 10.2 & 9.5 & 0.883 \\
\hline
\end{tabular}

multidrug resistance p-glycoprotein (MRD PGP) [30]. Hyperactivity of MRD PGP induced by depression results in reduced transport of glucocorticoids to the brain, leading to glucocorticoid resistance [31]. It has been well documented that the discharge of corticosteroids caused by HPA hyperactivity in CVD patients leads to hypertension and hyperlipidemia [32]. Furthermore, a reduced heart rate and variability of this rate are more likely to be experienced by depressed subjects [33]. Such a reduction in the heart rate has been documented as a risk factor for cardiovascular diseases [34] including myocardial infarction and sudden cardiac death [35].

Inflammatory marker levels are higher than normal in depressed patients with CVD. One hypothesis is that depression itself promotes a mild inflammatory response, which unhealthy practices such as inactivity and cigarette smoking may foster, and leads to deregulation of hormonal

Table 3 Continuous variables according to depression categories among subjects

\begin{tabular}{llll}
\hline Variables & \multicolumn{2}{c}{ Severe Depression } & P \\
& Absent $(\mathbf{N}=\mathbf{1 7 7})$ & Present $(\mathbf{N}=\mathbf{6 3})$ & \\
\hline Age & $62.18 \pm 15.52$ & $63.33 \pm 15.09$ & 0.611 \\
Income (\$) & $404.40 \pm 201.10$ & $396.50 \pm 184.83$ & 0.798 \\
MUFAs (g/day) & $18.33 \pm 6.08$ & $16.53 \pm 6.36$ & 0.540 \\
PUFAs (g/day) & $16.22 \pm 10.16$ & $12.61 \pm 9.67$ & 0.014 \\
SFAs (g/day) & $17.77 \pm 6.09$ & $17.07 \pm 6.13$ & 0.432 \\
TD F(g/day) & $16.02 \pm 6.60$ & $13.11 \pm 5.59$ & 0.002 \\
BMl (kg/m $)$ & $28.54 \pm 5.37$ & $27.75 \pm 5.10$ & 0.298 \\
WHR & $0.99 \pm 0.19$ & $1.05 \pm 0.20$ & 0.032 \\
Carbohydrates (g/day) & $245.83 \pm 63.49$ & $220.12 \pm 49.95$ & 0.004 \\
FBS (mg/dl) & $111.80 \pm 54.63$ & $124.93 \pm 72.02$ & 0.135 \\
SBP (mmHg) & $143.14 \pm 18.07$ & $149.68 \pm 17.04$ & 0.011 \\
DBP(mmHg) & $94.33 \pm 13.37$ & $96.88 \pm 13.44$ & 0.196 \\
TC (mg/dl) & $196.55 \pm 37.23$ & $213.69 \pm 33.96$ & 0.001 \\
LDL (mg/dl) & $142.02 \pm 26.35$ & $148.39 \pm 21.98$ & 0.633 \\
HDL (mg/dl) & $60.81 \pm 13.02$ & $62.20 \pm 16.17$ & 0.346 \\
TG (mg/dl) & $160.63 \pm 80.36$ & $160.61 \pm 66.16$ & 0.999 \\
\hline
\end{tabular}

systems (HPA) and increased susceptibility to infection. One very sensitive inflammatory marker, $\mathrm{C}$-reactive protein (hsCRP), was shown by Kaptoge et al. [36] to be a specific risk factor for CVD. C-reactive protein is secreted by the liver, mainly in response to IL-1 and IL-6, which are proinflammatory cytokines [37]. Secretion of these cytokines is promoted by immune stimuli and an imbalance in them could be involved in the pathophysiology of depression. IL6 , a particularly potent stimulator of the HPA axis, is secreted as part of the response to stress. This could imply a cascade effect among physiological mechanisms and biomarkers, which acting individually or collectively might enhance depression and increase the risk for cardiovascular disease [38].

During depression there are increased levels of radical nitrogen species (RNS) and reactive oxygen species (ROS) such as peroxide, and the activities of pro-oxidant enzymes such as xanthine oxidase (XO) are also increased, nitric oxide (NO) levels are changed and there are indications of oxidative and nitrosative stress (O\&NS) damage to fatty acids and DNA [39]. Peroxide circulates in the blood, and a recent case-control study by Maes et al. [40] showed that major depression patients have significantly higher plasma peroxide levels than normal individuals.

There is also strong evidence that depression increases oxidative damage to tissues $[41,42]$. Malondialdehyde (MDA), which can modify proteins and generate advanced lipoxidation end (ALE) products, is a by-product of polyunsaturated fatty acid peroxidation and is a

Table 4 AMI risk by depression before and after adjustment $(\mathrm{N}=\mathbf{2 4 0})$

\begin{tabular}{lccc}
\hline Severe Depression & OR & $\mathbf{9 5 \% ~ C . I ~}$ & $\mathbf{p}$ \\
\hline Absent vs present (177/63) & 3.1 & $1.7-5.7$ & $0.000^{\mathrm{a}}$ \\
Absent vs present (177/63) & 2.6 & $1.1-5.8$ & $0.025^{\mathrm{b}}$ \\
\hline
\end{tabular}

${ }^{\mathrm{a}}$ Before adjustment; ${ }^{\mathrm{b}} \mathrm{Adjustment}$ for other variables in unconditional binary logistic regression model controlling for anthropometrics parameter, lipid profile, socio-demographic status, and nutrient variables. 
widely-used indicator of oxidative stress. Its serum levels are significantly elevated in major depression [43]. ALEs are pro-inflammatory and therefore detrimental, weakening antioxidant defences and impairing DNA repair. They also have a key role in atherosclerosis and neurodegenerative disorders [44].

In the present study, polyunsaturated fatty acids (PUFAs) of those with severe depression were lower than in individuals with minor or moderate depression. Also, studies have demonstrated that a food frequency questionnaire (FFQ) can predict the concentration of PUFAs in the blood [45,46]. Several epidemiological [47] and case-control studies have demonstrated that a lower level of PUFAs is linked with depression [41,48-50] and CVD [51]. The mechanisms that affect PUFAs are unclear. However, one mechanism involves the regulation of the serotonergic [52] and dopaminergic systems [53]. Low levels of PUFAs predict low levels of 5-hydroxyindolacetic acid, a major metabolite of serotonin and an anti-depressant, in cerebrospinal fluid [54].

There are many functional interactions between dopaminergic systems and other systems including the serotoninergic, glutamatergic, GABAergic and cholinergic systems, which are related to behavioural processes [55]. PUFA deficiency deregulates the blood brain barrier [56], which is important for controlling mood disorders [57-59]. Moreover, major depression is associated with over-activity of the inflammatory response, affecting cytokines and alpha-interferon [60,61]. The pro-inflammatory series of eicosanoids are significantly affected by polyunsaturated fatty acids [62].

This study has demonstrated a significant association between severe depression and important dietary intake such as TDF and carbohydrates. A recent case-control study demonstrated significantly lower levels of dietary fiber in depressed patients [63]. Individuals who consume low fiber in their diets have low levels of many essential nutrients including carbohydrates and unsaturated fatty acids [64], and high levels of rapidly digested starches [65]. Dietary fiber affects depression itself and depression outcomes. It modulates serum lipids [66], blood pressure [67], inflammation [68], and waist-hip ratio (WHR) [69]. A diet rich in fiber also contains hundreds of phytochemicals [70], which protect neurons against injury by stimulating the production of several antioxidant enzymes, neurotrophic factors, protein chaperones and other proteins that provide neural protection against injury and disease [71].

There was a relationship between the level of severe depression and carbohydrate intake in the subjects. Carbohydrates influence mood and behavior [72,73], yet the mechanisms underlying such effects are unclear. However, carbohydrates may activate neurobiochemical pathways such as brain neurotransmitters that play a role in depression $[57,58]$. A diet rich in carbohydrates results in changes in blood glucose levels [74], stimulating the release of insulin. Insulin supplies cells with sugars and induces the transport of tryptophan (TRP) to the brain [75], by increasing plasma TRP levels compared to other large neutral amino acids (LNAAs) [57,58]. Therefore, carbohydrate intake induces an increase in the TRP/ LNAA ratio, causing LNAAs to enter skeletal muscles $[58,59]$.

It has been reported that the waist-hip ratio (WHR) is correlated with psychosocial factors [76], such as depression [77]. Furthermore, the body mass index (BMI) is weakly associated with depression, and abnormalities of the HPA axis and higher WHR is evident in patients suffering major depression [78].

Although several studies have documented that cigarette smoking is a risk factor in depressed patients $[79,80]$. We found no such correlation $[49,81,82]$. In this study, married subjects experienced fewer symptoms of depression, indicating that the presence of support affected depression in a positive manner $[81,83]$. There was no link between symptoms of depression and demographic factors such as age, sex, education or family history of CHD [84].

\section{Limitation of the study and conclusion}

This case-control study investigated hospitalized AMI patients only and further studies are required to investigate an association between depression and AMI among non-hospitalized patients. The present study demonstrated that severe depression symptoms are independent risk factors for AMI. Furthermore, severe depression was associated with an unhealthy diet and AMI risk factors. On the basis of these findings, there are several recommendations for future research. First, validation of the present findings is required as this is the first study concerning the population in Ilam province. A larger sample size is required, particularly for the investigation of socio-demographic characteristics. Furthermore, new risk factors such as C-reactive protein, malondialdehyde (MDA) and homocysteine should be investigated in the Ilam province, as they have been linked with depression and the risk of AMI worldwide.

\footnotetext{
Abbreviations

AMI: Acute myocardial infarction; ANS: autonomic nervous system; BMI: Body mass index; BP: Blood pressure; CES-D: Center for Epidemiologic Studies Depression Scale; CHD: Coronary heart disease; CVD: Cardiovascular vascular disease; DBP: Diastolic blood pressure; FBS: Fasting blood sugar; FFQ: Food frequency questionnaire; GABA: gamma-aminobutyric acid; HDL: High density lipoprotein; HPA: Hypothalamic-pituitary-adrenal; LDL: Low density lipoprotein; MRD PGP: Multidrug resistance p-glycoprotein; MUFA: Monounsaturated fatty acid; PUFA: Polyunsaturated fatty acids; SBP: Systolic blood pressure; SFA; Saturated fatty acids; TC: Total cholesterol; TDF: Total dietary fiber; TG: Triglyceride; WHR: Waist-hip ratio; \$: Dollar.
} 


\section{Acknowledgements}

We would like to express thanks to the population of llam Province. We wish to express our sincerest appreciation to all participants in this study, particularly patients who suffered from AMI. Furthermore, we would like to thank Ilam Medical University and Mostafa Hospital for supporting this study, particularly the nurses and staff from the coronary care unit (CCU) and post CCU ward.

\section{Author details}

'Department of Nutrition and Dietetics, Faculty of Medicine and Health Sciences, University Putra Malaysia, 43400 UPM, Serdang, Selangor, Malaysia. ${ }^{2}$ Department of Medicine, Faculty of Medicine and Health Sciences, llam Medical University, 6939177143, Banganjab, Ilam, Iran. ${ }^{3}$ Department of Medicine, Faculty of Medicine and Health Sciences, University Putra Malaysia, 43400 UPM, Serdang, Selangor, Malaysia. ${ }^{4}$ Department of Community Health, Faculty of Health, Tehran Medical Branch, Islamic Azad University, Zargandeh, 19168, Tehran, Iran.

\section{Authors' contributions}

TY designed, collected the data, interpretation of the results and helped draft the manuscript. KS provided the patients and controls, assisted with interpretation of the results and helped draft the manuscript. FAR assisted in design and interpretation of the results. MK assisted with interpretation of the results. SA assisted with collected the data, interpretation of the results and helped draft the manuscript. SOJ provided the patients and controls, assisted with interpretation of the results. WTW was a co-supervisor for this study. GA assisted with collected the data, interpretation of the results. All authors read and approved the final manuscript.

\section{Authors' information}

TY: Master Student in Nutritional Sciences at University Putra Malaysia. KS: Cardiologist and Lecture in Ilam Medical University and Head of the Mostafa Hospital, Iran. FAR and WTW: Cardiologist and Lecturer at University Putra Malaysia. MK: Nutritionist and Lecturer at University Putra Malaysia. SA: Master Student in Community Health Science. SJP: Orthopaedist at the Mostafa Hospital. GA is a nurse at the Mostafa Hospital.

\section{Competing interests}

The authors declare that they have no competing interests.

Received: 14 October 2010 Accepted: 18 November 2010 Published: 18 November 2010

\section{References}

1. Hatmi ZN, Tahvildari S, Motlag G, Kashani S: Prevalence of coronary artery disease risk factors in Iran: a population based survey. BMC Cardiovascular Disorders 2007, 7:32.

2. Luszczynska A, Scholz U, Sutton S: Planning to change diet: A controlled trial of an implementation intentions training intervention to reduce saturated fat intake among patients after myocardial infarction. Journal of Psychosomatic Research 2007, 63:491-497.

3. Marniemi J, Alanen E, Impivaara O, SeppSnen R, Hakala P, Rajala T, Ronnemaa T: Dietary and serum vitamins and minerals as predictors of myocardial infarction and stroke in elderly subjects. Nutrition, Metabolism and Cardiovascular Diseases 2005, 15:188-197.

4. Song R, Kim HS: Comparing actual food intake and serum lipid profile with perceived dietary behavior in Korean myocardial infarction patients. Nutrition Research 2002, 22:891-900.

5. Rugulies R: Depression as a predictor for coronary heart disease a review and meta-analysis. American Journal of Preventive Medicine 2002, 23:51-61.

6. Lesperance F, Frasure-Smith N, Talajic M, Bourassa MG: Five-year risk of cardiac mortality in relation to initial severity and one-year changes in depression symptoms after myocardial infarction. circulation 2002, 105:1049.

7. Carney RM, Freedland KE, Miller GE, Jaffe AS: Depression as a risk factor for cardiac mortality and morbidity: A review of potential mechanisms. Journal of Psychosomatic Research 2002, 53:897-902.

8. Mikolajczyk RT, El Ansari W, Maxwell AE: Food consumption frequency and perceived stress and depressive symptoms among students in three European countries. Nutrition Journal 2009, 8:31.
9. Whang W, Kubzansky LD, Kawachi I, Rexrode KM, Kroenke CH, Glynn RJ, Garan H, Albert CM: Depression and Risk of Sudden Cardiac Death and Coronary Heart Disease in Women: Results From the Nurses' Health Study. Journal of the American College of Cardiology 2009, 53:950-958.

10. Balog P, Janszky I, Leineweber C, Blom M, Wamala SP, Orth-Gomq K: Depressive symptoms in relation to marital and work stress in women with and without coronary heart disease. The Stockholm Female Coronary Risk Study. Journal of Psychosomatic Research 2003, 54:113-119.

11. Davidson K, Jonas BS, Dixon KE, Markovitz JH: Do depression symptoms predict early hypertension incidence in young adults in the CARDIA study? Archives of Internal Medicine 2000, 160:1495.

12. Jonas BS, Franks P, Ingram DD: Are symptoms of anxiety and depression risk factors for hypertension? Longitudinal evidence from the National Health and Nutrition Examination Survey I Epidemiologic Follow-up Study. Archives of family medicine 1997, 6:43.

13. Strik JJ, Honig A, Maes M: Depression and myocardial infarction: relationship between heart and mind. Progress in NeuroPsychopharmacology and Biological Psychiatry 2001, 25:879-892.

14. Nicholson $A$, Kuper $H$, Hemingway $H$ : Depression as an aetiologic and prognostic factor in coronary heart disease: a meta-analysis of 6362 events among 146538 participants in 54 observational studies. European Heart Journal 2006, 27:2763.

15. Willett WC, Sampson L, Stampfer MJ, Rosner B, Bain C, Witschi J, Hennekens $\mathrm{CH}$, Speizer FE: Reproducibility and validity of a semiquantitative food frequency questionnaire. American Journal of Epidemiology 1985, 122:51.

16. Booya F, Bandarian F, Larijani B, Pajouhi M, Nooraei M, Lotfi J: Potential risk factors for diabetic neuropathy: a case control study. BMC neurology 2005, 5:24.

17. Ghasemi A, Zahedi Asl S, Mehrabi Y, Saadat N, Azizi F: Serum nitric oxide metabolite levels in a general healthy population: Relation to sex and age. Life Sciences 2008, 83:326-331.

18. Hashemian F, Khoshnood K, Desai MM, Falahati F, KasI S, Southwick S: Anxiety, depression, and posttraumatic stress in Iranian survivors of chemical warfare. JAMA 2006, 296:560.

19. Janghorbani M, Sharifirad GHR: Completed and attempted suicide in Ilam, Iran (1995û2002): Incidence and associated factors. Archives of Iranian Medicine 2005, 8:119-126.

20. Mofidi N, Ghazinour M, Salander-Renberg E, Richter J: Attitudes towards suicide among Kurdish people in Iran. Social psychiatry and psychiatric epidemiology 2008, 43:291-298.

21. Carney RM, Freedland KE, Rich MW, Jaffe AS: Depression as a risk factor for cardiac events in established coronary heart disease: a review of possible mechanisms. Annals of Behavioral Medicine 1995, 17:142-149.

22. Carney RM, Freedland KE, Steinmeyer B, Blumenthal JA, Berkman LF, Watkins LL, Czajkowski SM, Burg MM, Jaffe AS: Depression and five year survival following acute myocardial infarction: A prospective study. Journal of Affective Disorders 2008, 109:133-138.

23. Glassman AH, Shapiro PA: Depression and the course of coronary artery disease. American Journal of Psychiatry 1998, 155:4.

24. Grace SL, Abbey SE, Kapral MK, Fang J, Nolan RP, Stewart DE: Effect of depression on five-year mortality after an acute coronary syndrome. The American Journal of Cardiology 2005, 96:1179-1185.

25. Carney RM, Freedland KE, Miller GE, Jaffe AS: Depression as a risk factor for cardiac mortality and morbidity: A review of potential mechanisms. Journal of Psychosomatic Research 2002, 53:897-902.

26. Horsten M, Wamala SP, Vingerhoets A, Orth-Gomer K: Depressive symptoms, social support, and lipid profile in healthy middle-aged women. Psychosomatic medicine 1997, 59:521.

27. Grace SL, Abbey SE, Pinto R, Shnek ZM, Irvine J, Stewart DE: Longitudinal course of depressive symptomatology after a cardiac event: effects of gender and cardiac rehabilitation. Psychosomatic medicine 2005, 67:52.

28. Wittstein IS: Depression, anxiety, and platelet reactivity in patients with coronary heart disease. European Heart Journal 2010, 31(13):1548-50.

29. Brydon L, Magid K, Steptoe A: Platelets, coronary heart disease, and stress. Brain, behavior, and immunity 2006, 20:113-119.

30. Murck H, Song C, Horrobin DF, Uhr M: Ethyl-eicosapentaenoate and dexamethasone resistance in therapy-refractory depression. The International Journal of Neuropsychopharmacology 2004, 7:341-349.

31. Pariante CM: The glucocorticoid receptor: part of the solution or part of the problem? Journal of Psychopharmacology 2006, 20:79. 
32. Musselman DL, Evans DL, Nemeroff CB: The relationship of depression to cardiovascular disease: epidemiology, biology, and treatment. Archives of general psychiatry 1998, 55:580.

33. Stein PK, Carney RM, Freedland KE, Skala JA, Jaffe AS, Kleiger RE, Rottman JN: Severe depression is associated with markedly reduced heart rate variability in patients with stable coronary heart disease. Journal of Psychosomatic Research 2000, 48:493-500.

34. Chattipakorn N, Incharoen T, Kanlop N, Chattipakorn S: Heart rate variability in myocardial infarction and heart failure. International Journal of Cardiology 2007, 120:289-296.

35. Fauchier L, Babuty D, Cosnay P, Fauchier JP: Prognostic value of heart rate variability for sudden death and major arrhythmic events in patients with idiopathic dilated cardiomyopathy. Journal of the American College of Cardiology 1999, 33:1203-1207.

36. Kaptoge S, Di Angelantonio E, Lowe G, Pepys MB, Thompson SG, Collins R, Danesh J, Bladbjerg EM, Jespersen J: C-reactive protein concentration and risk of coronary heart disease, stroke, and mortality: an individual participant meta-analysis. Lancet 2010, 375:132-140.

37. Yap SH, Moshage HJ, Hazenberg BPC, Roelofs HMJ, Bijzet J, Limburg PC, Aarden LA, Van Rijswijk MH: Tumor necrosis factor (TNF) inhibits interleukin (IL)-1 and/or IL-6 stimulated synthesis of C-reactive protein (CRP) and serum amyloid $A(S A A)$ in primary cultures of human hepatocytes. Biochimica et Biophysica Acta (BBA)-Molecular Cell Research 1991, 1091:405-408.

38. Uchakin PN, Tobin B, Cubbage M, Marshall G Jr, Sams C: Immune responsiveness following academic stress in first-year medical students. Journal of Interferon \& Cytokine Research 2001, 21:687-694.

39. Maes M, Galecki $P$, Chang YS, Berk M: A review on the oxidative and nitrosative stress (O\&NS) pathways in major depression and their possible contribution to the (neuro) degenerative processes in that illness. Progress in Neuro-Psychopharmacology and Biological Psychiatry 2010.

40. Maes M, Mihaylova I, Kubera M, Uytterhoeven M, Vrydags N, Bosmans E: Increased plasma peroxides and serum oxidized low density lipoprotein antibodies in major depression: Markers that further explain the higher incidence of neurodegeneration and coronary artery disease. Journal of Affective Disorders 2010, 125:287-294.

41. Edwards R, Peet M, Shay J, Horrobin D: Omega-3 polyunsaturated fatty acid levels in the diet and in red blood cell membranes of depressed patients. Journal of Affective Disorders 1998, 48:149-155.

42. Maes M: Major depression and activation of the inflammatory response system. Cytokines, stress, and depression 1999, 25-46.

43. Khanzode SD, Dakhale GN, Khanzode SS, Saoji A, Palasodkar R: Oxidative damageand major depression: the potential antioxidant action of selective serotonin re-uptake inhibitors. Redox Report 2003, 8:365-370.

44. Aldini G, le Donne I, Facino RM, Milzani A, Carini M: Intervention strategies to inhibit protein carbonylation by lipoxidation derived reactive carbonyls. Medicinal Research Reviews 2007, 27:817-868.

45. Bonaa KH, Bjerve KS, Nordoy A: Habitual fish consumption, plasma phospholipid fatty acids, and serum lipids: the Tromso study. American Journal of Clinical Nutrition 1992, 55:1126.

46. Silverman DI, Reis GJ, Sacks FM, Boucher TM, Pasternak RC: Usefulness of plasma phospholipid N-3 fatty acid levels in predicting dietary fish intake in patients with coronary artery disease. The American Journal of Cardiology 1990, 66:860-862.

47. Hibbeln JR, Nieminen LRG, Blasbalg TL, Riggs JA, Lands WEM: Healthy intakes of $n-3$ and $n-6$ fatty acids: estimations considering worldwide diversity. American Journal of Clinical Nutrition 2006, 83:51483.

48. Freeman MP, Hibbeln JR, Wisner $\mathrm{KL}$, Davis JM, Mischoulon D, Peet M, Keck PE Jr, Marangell LB, Richardson AJ, Lake J: Omega-3 fatty acids: evidence basis for treatment and future research in psychiatry. Journal of Clinical Psychiatry 2006, 67:1954-1967.

49. Parker GB, Heruc GA, Hilton TM, Olley A, Brotchie H, Hadzi-Pavlovic D, Friend C, Walsh WF, Stocker R: Low levels of docosahexaenoic acid identified in acute coronary syndrome patients with depression. Psychiatry research 2006, 141:279-286.

50. Peet M, Murphy B, Shay J, Horrobin D: Depletion of omega-3 fatty acid levels in red blood cell membranes of depressive patients. Biological Psychiatry 1998, 43:315-319.

51. Yokoyama M, Origasa H, Matsuzaki M, Matsuzawa $Y$, Saito $Y$, Ishikawa $Y$, Oikawa S, Sasaki J, Hishida H, Itakura H: Effects of eicosapentaenoic acid on major coronary events in hypercholesterolaemic patients (JELIS): a randomised open-label, blinded endpoint analysis. The Lancet 2007 369:1090-1098

52. Hibbeln JR, Salem N Jr: Dietary polyunsaturated fatty acids and depression: when cholesterol does not satisfy. American Journal of Clinical Nutrition 1995, 62:1.

53. Zimmer L, Delpal S, Guilloteau D: Chronic n-3 polyunsaturated fatty acid deficiency alters dopamine vesicle density in the rat frontal cortex. Neuroscience letters 2000, 284:25-28.

54. Hibbeln JR, Umhau JC, Linnoila M, George DT, Ragan PW, Shoaf SE, Vaughan MR, Rawlings R, Salem Jr N: A replication study of violent and nonviolent subjects: cerebrospinal fluid metabolites of serotonin and dopamine are predicted by plasma essential fatty acids. Biological Psychiatry 1998, 44:243-249.

55. Chalon S, Vancassel S, Zimmer L, Guilloteau D, Durand G: Polyunsaturated fatty acids and cerebral function: focus on monoaminergic neurotransmission. Lipids 2001, 36:937-944.

56. Ziylan ZY, Bernard GC, Lefauconnier JMA, Durand GA, Bourre JME: Effect of dietary n-3 fatty acid deficiency on blood-to-brain transfer of sucrose, [alpha]-aminoisobutyric acid and phenylalanine in the rat. Neuroscience letters 1992, 137:9-13.

57. Curzon G: Effects of food intake on brain transmitter amine precursors and amine synthesis. Psychopharmacology and food 1985, 59-70.

58. Fernstrom JD, Wurtman RJ: Brain serotonin content: physiological dependence on plasma tryptophan levels. Science 1971, 173:149.

59. Markus CR: Effects of carbohydrates on brain tryptophan availability and stress performance. Biological Psychology 2007, 76:83-90.

60. Bonaccorso S, Puzella A, Marino V, Pasquini M, Biondi M, Artini M, Almerighi C, Levrero M, Egyed B, Bosmans E: Immunotherapy with interferon-alpha in patients affected by chronic hepatitis $C$ induces an intercorrelated stimulation of the cytokine network and an increase in depressive and anxiety symptoms. Psychiatry research 2001, 105:45-55.

61. Song C, Lin A, Bonaccorso S, Heide C, Verkerk R, Kenis G, Bosmans E, Scharpe $S$, Whelan $A$, Cosyns $P$ : The inflammatory response system and the availability of plasma tryptophan in patients with primary sleep disorders and major depression. Journal of Affective Disorders 1998, 49:211-219.

62. Sontrop J, Campbell MK: [omega]-3 polyunsaturated fatty acids and depression: A review of the evidence and a methodological critique. Preventive Medicine 2006, 42:4-13.

63. Park JY, You JS, Chang KJ: Dietary taurine intake, nutrients intake, dietary habits and life stress by depression in Korean female college students: a case-control study. Journal of Biomedical Science 2010, 17:S40.

64. Ballesteros MN, Cabrera RM, Saucedo MS, Yepiz-Plascencia GM, Ortega MI, Valencia ME: Dietary fiber and lifestyle influence serum lipids in free living adult men. Journal of the American College of Nutrition 2001, 20:649.

65. Mann Jl, Cummings JH: Possible implications for health of the different definitions of dietary fibre. Nutrition, Metabolism and Cardiovascular Diseases 2009, 19:226-229.

66. Jenkins DJA, Kendall CWC, Axelsen M, Augustin LSA, Vuksan V: Viscous and nonviscous fibres, nonabsorbable and low glycaemic index carbohydrates, blood lipids and coronary heart disease. Current opinion in lipidology 2000, 11:49.

67. Li J, Wang J, Kaneko T, Qin LQ, Sato A: Effects of fiber intake on the blood pressure, lipids, and heart rate in Goto Kakizaki rats. nutrition 2011, 20:1003-1007.

68. King DE, Egan BM, Geesey ME: Relation of dietary fat and fiber to elevation of C-reactive protein. The American Journal of Cardiology 2003, 92:1335-1339.

69. Lairon D, Bertrais S, Vincent S, Arnault N, Galan P, Boutron MC, Hercberg S: Dietary fibre intake and clinical indices in the French Supplementation en Vitamines et Minqraux AntioXydants (SU. VI. MAX) adult cohort. Proceedings of the Nutrition Society 2007, 62:11-15.

70. McGuire M, Beerman KIA: Nutritional Sciences: From Fundamentals to Food. Thomson Wadsworth, Belmont, CA; 2007.

71. Mattson MP, Cheng A: Neurohormetic phytochemicals: low-dose toxins that induce adaptive neuronal stress responses. Trends in Neurosciences 2006, 29:632-639.

72. Argyropoulos SV, Hood SD, Adrover M, Bell CJ, Rich AS, Nash JR, Rich NC, Witchel HJ, Nutt DJ: Tryptophan depletion reverses the therapeutic effect of selective serotonin reuptake inhibitors in social anxiety disorder. Biological Psychiatry 2004, 56:503-509. 
73. Klaassen T, Klumperbeek J, Deutz NEP, van Praag HM, Griez E: Effects of tryptophan depletion on anxiety and on panic provoked by carbon dioxide challenge. Psychiatry research 1998, 77:167-174.

74. Benton D, Ruffin MP, Lassel T, Nabb S, Messaoudi M, Vinoy S, Desor D, Lang V: The delivery rate of dietary carbohydrates affects cognitive performance in both rats and humans. Psychopharmacology 2003, 166:86-90.

75. Saljoughian M: Nutrition and Clinical Depression. US Pharm 2009, 11:19.

76. Laws A, Terry RB, Barrett-Connor E: Behavioral covariates of waist-to-hip ratio in Rancho Bernardo. American Journal of Public Health 1990, 80:1358.

77. Wing RR, Matthews KA, Kuller LH, Meilahn EN, Plantinga P: Waist to hip ratio in middle-aged women. Associations with behavioral and psychosocial factors and with changes in cardiovascular risk factors. Arteriosclerosis, Thrombosis, and Vascular Biology 1991, 11:1250.

78. Ahlberg AC, Ljung T, Rosmond R, McEwen B, Holm G, Akesson HO, $B j \div$-rntorp P: Depression and anxiety symptoms in relation to anthropometry and metabolism in men. Psychiatry research 2002, 112:101-110.

79. Blumenthal JA, Williams RS, Wallace AG, Williams RB Jr, Needles TL: Physiological and psychological variables predict compliance to prescribed exercise therapy in patients recovering from myocardial infarction. Psychosomatic medicine 1982, 44:519.

80. DiMatteo MR, Lepper HS, Croghan TW: Depression is a risk factor for noncompliance with medical treatment: meta-analysis of the effects of anxiety and depression on patient adherence. Archives of Internal Medicine 2000, 160:2101.

81. Empana JP, Sykes DH, Luc G, Juhan-Vague I, Arveiler D, Ferrieres J, Amouyel P, Bingham A, Montaye M, Ruidavets JB: Contributions of depressive mood and circulating inflammatory markers to coronary heart disease in healthy European men: the Prospective Epidemiological Study of Myocardial Infarction (PRIME). circulation 2005, 111:2299.

82. Ziegelstein RC, Fauerbach JA, Stevens SS, Romanelli J, Richter DP, Bush DE: Patients with depression are less likely to follow recommendations to reduce cardiac risk during recovery from a myocardial infarction. Archives of Internal Medicine 2000, 160:1818.

83. Frasure-Smith N, Lesperance F, Gravel G, Masson A, Juneau M, Talajic M, Bourassa MG: Social support, depression, and mortality during the first year after myocardial infarction. circulation 2000, 101:1919.

84. Frasure-Smith N, Lesperance F: Depression and anxiety as predictors of 2year cardiac events in patients with stable coronary artery disease. Archives of general psychiatry 2008, 65:62.

doi:10.1186/1476-511X-9-133

Cite this article as: Yary et al: Contribution of diet and major depression to incidence of acute myocardial infarction (AMI). Lipids in Health and Disease 2010 9:133.

\section{Submit your next manuscript to BioMed Central and take full advantage of:}

- Convenient online submission

- Thorough peer review

- No space constraints or color figure charges

- Immediate publication on acceptance

- Inclusion in PubMed, CAS, Scopus and Google Scholar

- Research which is freely available for redistribution

Submit your manuscript at www.biomedcentral.com/submit
Biomed Central 